3. Nori $\mathrm{P}$, Cowman $\mathrm{K}$, Chen V, et al. Bacterial and fungal coinfections in COVID-19 patients hospitalized during the New York City pandemic surge. Infect Control Hosp Epidemiol 2020;42:84-88.

4. Giacobbe DR, Battaglini D, Ball L, et al. Bloodstream infections in critically ill patients with COVID-19. Eur J Clin Investig 2020;50:e13319.

5. Cates J, Lucero-Obusan C, Dahl RM, et al. Risk for in-hospital complications associated with COVID-19 and influenza-Veterans' Health Administration, United States, October 1, 2018-May 31, 2020. Morbid Mortal Wkly Rep 2020.

6. Ripa M, Galli L, Poli A, et al. Secondary infections in patients hospitalized with COVID-19: incidence and predictive factors. Clin Microbiol Infect 2020;69;1528-1534.
7. Bizzarro MJ, Conrad SA, Kaufman DA, Rycus P. Infections acquired during extracorporeal membrane oxygenation in neonates, children, and adults. Pediatr Crit Care Med 2011;12:277-281.

8. Shekar K, Badulak J, Peek G, et al. Extracorporeal Life Support Organization coronavirus disease 2019 interim guidelines: a consensus document from an international group of interdisciplinary extracorporeal membrane oxygenation providers. Am Soc Artif Intern Organs J 2020;66:707-721.

9. Barbaro RP, MacLaren G, Boonstra PS, et al. Extracorporeal membrane oxygenation support in COVID-19: an international cohort study of the Extracorporeal Life Support Organization registry. Lancet 2020;396: 1071-1078.

\title{
Predictors for in-hospital mortality from coronavirus disease 2019 (COVID-19) infection among adults aged $18-65$ years
}

\author{
Ashish Bhargava MD, FACP (1), Mamta Sharma MD, Elisa Akagi MD, Susanna M. Szpunar PhD and \\ Louis Saravolatz MD, MACP, FIDSA \\ Ascension St John Hospital, Detroit, Michigan
}

As of October 13,2020, at least 37,867,739 cases of coronavirus disease 2019 (COVID-19) had been identified worldwide, including $\sim 7,804,699$ cases in the United States. ${ }^{1}$ Early data from the United States showed that $20 \%$ of deaths occurred in patients aged $20-64$ years and $80 \%$ occurred in patients aged $\geq 65$ years. $^{2}$ Understanding the risk factors associated with mortality among adults aged $<65$ years may identify vulnerable patients. The purpose of the study was to identify factors present at the time of hospital admission that predicted in-hospital mortality from COVID-19 among adults aged $\leq 65$ years.

\section{Methods}

We conducted a retrospective study at a 776-bed, tertiary-care center. The study was approved by the Ascension St John Hospital Institutional Review Board. We included adult patients with confirmed COVID-19 by positive real-time reverse-transcriptase-polymerase chain reaction (RT-PCR) assay of a nasopharyngeal swab for severe acute respiratory coronavirus virus 2 (SARS-CoV-2) from March 8 to June 14, 2020. Patient demographics, comorbid conditions, presenting symptoms, initial vital signs, admission laboratory and radiological findings, and outcome variables were extracted from the electronic medical records.

Statistical analyses were performed using SPSS version 27.0 software (IBM, Armonk, NY). Univariable analyses were conducted using the Student $t$ test, the Mann-Whitney U test, and $\chi^{2}$ analysis. Variables that were significant or near-significant predictors of mortality $(P<.09)$ were entered into a multivariable logistic regression model using a forward likelihood ratio algorithm. For comorbidities, the Charlson weighted index of comorbidity

Author for correspondence: Ashish Bhargava, E-mail: Ashish.bhargava@ascension. org. Or Louis Saravolatz, E-mail: louis.saravolatz@ascension.org

Cite this article: Bhargava A, et al. (2021). Predictors for in-hospital mortality from coronavirus disease 2019 (COVID-19) infection among adults aged 18-65 years. Infection Control \& Hospital Epidemiology, 42: 772-775, https://doi.org/10.1017/ ice. 2020.1390
(CWIC) score was used instead of individual comorbid conditions. ${ }^{3}$ Results from the regression are reported as odds ratios with $95 \%$ confidence intervals. All reported $P$ values are 2 -sided.

\section{Results}

In total, 265 hospitalized patients, ages 18-65 years, were included in this study. The mean age of the cohort was 50.4 years (SD, 10.7), $140(52.8 \%)$ were male, and $226(85.3 \%)$ were black/AfricanAmerican. The mean body mass index of the cohort was 35.8 $\mathrm{kg} / \mathrm{m}^{2}$ (SD, 9.3). The mean duration of symptoms prior to hospitalization was 5.8 days (SD, 3.8). Severe pneumonia was diagnosed in 49 patients (18.5\%). Mechanical ventilation was required for 66 patients $(24.9 \%)$. Overall, 214 patients $(80.8 \%)$ improved clinically and survived to discharge.

The in-hospital case fatality rate (CFR) was $19.2 \%$ (51 of 265). Patients who died were significantly older (mean age, 53.4 years $[\mathrm{SD}, 9.4]$ vs 49.7 years [SD, 10.8]) than patients who survived $(P=.03)$. Patients who died were significantly more likely to have hypertension, diabetes with chronic complications, hemiplegia, preexisting renal disease, liver disease, and a diagnosis of malignancy (Table 1). The prevalence of lymphocytopenia and thrombocytopenia were higher among patients who died than those who survived.

The Quick Sequential Organ Failure Assessment (qSOFA) score $(0-3)$ is composed of 3 clinical parameters with 1 point allotted to each of these parameters: systolic blood pressure $\leq 100 \mathrm{~mm} \mathrm{Hg}$, respiratory rate $\geq 22$ breaths per minute, and altered mental status. For patients with qSOFA scores of $0,1,2$, and 3 at the time of hospital admission, the mortality rates were $9.7 \%, 21.1 \%, 41.7 \%$, and $60 \%$, respectively $(P<.0001)$.

The final multivariable logistic regression model included 4 variables that predicted increased odds of death in patients with COVID-19 infection: Charlson score, presence of hypertension, qSOFA, and thrombocytopenia at the time of hospital admission (Table 2).

(c) The Author(s), 2020. Published by Cambridge University Press on behalf of The Society for Healthcare Epidemiology of America. This is an Open Access article, distributed under the terms of the Creative Commons Attribution licence (http://creativecommons.org/licenses/by/4.0/), which permits unrestricted re-use, distribution, and reproduction in any medium, provided the original work is properly cited. 
Table 1. Univariable Analysis of Predictors for in-Hospital Mortality Among Adults, Aged 18-65 Years From CoVID-19 Infection at the Time of Hospital Admission

\begin{tabular}{|c|c|c|c|c|}
\hline Characteristic & Survivors ( $n=214)$, No. $(\%)$ & Nonsurvivors ( $n=51$ ), No. (\%) & OR $(95 \% \mathrm{Cl})$ & $P$ Value \\
\hline \multicolumn{5}{|l|}{ Sex, no. (\%) } \\
\hline Male & $113(52.8)$ & $27(52.9)$ & $1.0(0.5-1.9)$ & .98 \\
\hline \multicolumn{5}{|l|}{ Race, no. (\%) } \\
\hline White & $28(13.1)$ & $5(9.8)$ & & .80 \\
\hline Other & $5(2.3)$ & $1(2.0)$ & & \\
\hline $\mathrm{BMI}$, mean $\pm \mathrm{SD}$ & $35.4 \pm 8.8$ & $37.7 \pm 11.1$ & & .12 \\
\hline \multicolumn{5}{|l|}{ Admission source } \\
\hline Home & $184(86.01)$ & $39(76.5)$ & $1.9(0.9-4.0)$ & .10 \\
\hline Nursing facility & $30(14.0)$ & $12(28.6)$ & & \\
\hline \multicolumn{5}{|l|}{ Comorbidities, no. (\%) } \\
\hline Myocardial infarction & $7(3.3)$ & $3(5.9)$ & $1.8(0.5-7.4)$ & .38 \\
\hline Congestive heart failure & $20(9.3)$ & $3(5.9)$ & $0.6(0.2-2.1)$ & .43 \\
\hline Peripheral vascular disease & $10(4.7)$ & $3(5.9)$ & $1.3(0.3-4.8)$ & .72 \\
\hline Cerebrovascular disease & $21(9.9)$ & $2(3.9)$ & $0.4(0.1-1.6)$ & .18 \\
\hline Dementia & $11(5.1)$ & $4(7.8)$ & $1.6(0.5-5.2)$ & .45 \\
\hline Chronic pulmonary disease & $41(19.2)$ & $14(27.5)$ & $1.6(0.8-3.2)$ & .19 \\
\hline Connective tissue disease & $2(0.9)$ & $1(2.0)$ & $2.1(0.2-23.8)$ & .53 \\
\hline Peptic ulcer disease & $7(3.3)$ & $1(2.0)$ & $0.6(0.07-4.9)$ & .62 \\
\hline Metastatic solid tumor & $0(0.0)$ & $1(2.0)$ & $\ldots$ & $\ldots$ \\
\hline Mild liver disease & $1(0.5)$ & $2(3.9)$ & $8.7(0.8-105.3)$ & .04 \\
\hline Moderate-severe liver disease & $1(0.5)$ & $2(3.9)$ & $8.7(0.8-97.8)$ & .04 \\
\hline AIDS & $3(1.4)$ & $0(0.0)$ & $\ldots$ & $\ldots$ \\
\hline Median CWIC $\left(25^{\text {th }}-75^{\text {th }}\right)$ & $0.0(0,1)$ & $1.0(0-3.0)$ & & $<.0001$ \\
\hline Hypertension & $129(60.3)$ & $42(82.4)$ & $3.1(1.4-6.6)$ & .003 \\
\hline Current tobacco smoker & $17(7.9)$ & $5(10.0)$ & $1.3(0.5-3.7)$ & .67 \\
\hline Obesity & $149(71.0)$ & $39(76.5)$ & $1.3(0.7-2.7)$ & .43 \\
\hline History of sick contact & 70 (33.8) & $1615(32.0)$ & $0.9(0.5-1.8)$ & .81 \\
\hline \multicolumn{5}{|l|}{ Symptoms, no. (\%) } \\
\hline Fever & $147(69.0)$ & $33(66.0)$ & $0.9(0.5-1.7)$ & .68 \\
\hline Shortness of breath & $156(73.5)$ & $41(82.0)$ & $1.7(0.8-3.6)$ & .20 \\
\hline Cough & $160(75.5)$ & $34(69.4)$ & $0.7(0.4-1.5)$ & .38 \\
\hline Loss of taste & $35(16.7)$ & $5(10.4)$ & $0.6(0.2-1.6)$ & .28 \\
\hline \multicolumn{5}{|l|}{ Vitals on admission } \\
\hline Systolic BP, mean \pm SD & $135.6 \pm 23.7$ & $136.0 \pm 29.3$ & & .92 \\
\hline Diastolic BP, mean \pm SD & $76.7 \pm 15.9$ & $76.2 \pm 1729$ & & .85 \\
\hline
\end{tabular}


Table 1. (Continued)

\begin{tabular}{|c|c|c|c|c|}
\hline Characteristic & Survivors ( $n=214)$, No. $(\%)$ & Nonsurvivors ( $n=51$ ), No. (\%) & OR $(95 \% \mathrm{Cl})$ & $P$ Value \\
\hline Heart rate, mean \pm SD & $104.1 \pm 21.2$ & $112.7 \pm 21.0$ & & .02 \\
\hline Respiratory rate, mean \pm SD & $22.8 \pm 7.0$ & $27.1 \pm 8.4$ & & $<.0001$ \\
\hline Oxygen saturation, mean \pm SD & $0.94 \pm 0.06$ & $0.91 \pm 0.09$ & & .001 \\
\hline qSOFA scores & & & & $<.0001$ \\
\hline 1 & $105(49.1)$ & $28(54.9)$ & & \\
\hline 2 & $14(6.5)$ & $10(19.6)$ & & \\
\hline 3 & $2(0.9)$ & $3(5.9)$ & & \\
\hline Abnormal chest $x$-ray on admission, no. (\%) & $152(71.0)$ & $42(82.4)$ & $1.9(0.9-4.1)$ & .10 \\
\hline \multicolumn{5}{|l|}{ Laboratory findings on admission, no. (\%) } \\
\hline Elevated AST (>40 U/L) & $110(53.9)$ & $33(71.7)$ & $2.2(1.1-4.4)$ & .03 \\
\hline Elevated ALT (>40 U/L) & $81(38.8)$ & $15(30.6)$ & $0.7(0.4-1.4)$ & .29 \\
\hline Low serum protein $(<6.2 \mathrm{gm} / \mathrm{dL})$ & $6(2.9)$ & $5(10.2)$ & $3.8(1.1-13.1)$ & .02 \\
\hline Low serum albumin (<3.5 gm/dL) & $60(28.8)$ & $26(53.1)$ & $2.8(1.5-5.3)$ & .001 \\
\hline Elevated creatinine (from baseline) & $55(26.6)$ & $27(57.4)$ & $3.7(1.9-7.2)$ & $<.0001$ \\
\hline Positive blood culture on admission & $5(5.2)$ & $3(12.0)$ & $2.5(0.6-11.2)$ & .22 \\
\hline \multicolumn{5}{|l|}{ Clinical diagnosis, no. (\%) } \\
\hline Uncomplicated illness & $103(48.1)$ & $17(33.3)$ & & .008 \\
\hline Mild pneumonia & 79 (36.9) & $17(33.3)$ & & \\
\hline
\end{tabular}

Note. OR, odds ratio; $\mathrm{Cl}$, confidence interval; BMI, body mass index; SD, standard deviation; AIDS, acquired immunodeficiency syndrome; CWIC, Charlson weighted index of comorbidity; BP, blood pressure; AST, aspartate aminotransferase; ALT, alanine aminotransferase; CRP, C-reactive protein; qSOFA, quick sepsis-related organ-failure assessment.

Table 2. Multivariable Analysis of Predictors for In-Hospital Mortality Among Adults, Aged 18-65 Years From COVID-19 Infection at the Time of Hospital Admission

\begin{tabular}{lcc}
\hline Variables & OR $(95 \% \mathrm{Cl})$ & $P$ Value \\
\hline CWIC score & $1.3(1.1-1.6)$ & $<.0001$ \\
\hline Thrombocytopenia & $3.5(1.5-8.0)$ & .003 \\
\hline Hypertension & $2.8(1.1-6.8)$ & .03 \\
\hline qSOFA score of $1^{\mathrm{a}}$ & $3.1(1.3-7.8)$ & .02 \\
\hline qSOFA score of $2^{\mathrm{a}}$ & $6.2(1.8-20.9)$ & .003 \\
\hline${\text { qSOFA score of } 3^{\mathrm{a}}}^{\text {a }}$ & $15.2(1.7-135.2)$ & .02 \\
\hline
\end{tabular}

Note. OR, odds ratio; $\mathrm{Cl}$, confidence interval; $\mathrm{CWIC}$, Charlson weighted index of comorbidity; qSOFA, quick sepsis-related organ-failure assessment. qSOFA 1 has a score of 1, qSOFA 2 has a score of 2, and qSOFA 3 has a score of 3.

${ }^{a}$ Compared to a qSOFA score of zero.

\section{Discussion}

In our study, the CFR among patients aged $\leq 65$ years was $19.2 \%$, which is similar to previous US studies, in which mortality ranged from $8.3 \%$ to $22.7 \% .{ }^{4}$ The qSOFA score was introduced by the Sepsis-3 task force as a tool to assist in the early identification of patients at risk of sepsis. Patients with a qSOFA score of 2 or higher had a mortality rate of $24 \%$ compared to $3 \%$ among patients with a qSOFA score of $<2 .{ }^{5}$ In our study, a qSOFA score of 2 was associated with a mortality rate of $41.7 \%$.

Thrombocytopenia in critically ill patients usually suggests serious organ malfunction or physiologic decompensation, often evolving toward disseminated intravascular coagulation. In a meta-analysis, a lower platelet count was encountered in nonsurviving COVID-19 patients. ${ }^{6}$ In our study, $37.3 \%$ of nonsurvivors had thrombocytopenia on presentation compared to $13.6 \%$ of survivors.

Similar to clinical studies, we found that a higher Charlson score was an independent predictor of mortality. ${ }^{7-9}$ In terms of individual comorbidities, hypertension, diabetes with chronic complications, hemiplegia, renal disease, malignancy, and liver disease, were associated with mortality. Previous studies from China have reported mortality in patients with comorbidities of $10.5 \%$ for cardiovascular disease, $7.3 \%$ for diabetes, $6.3 \%$ for chronic respiratory disease, $6 \%$ for hypertension, and $5.6 \%$ for cancer. ${ }^{7}$ Previously, we reported that acute or pre-existing renal disease was an independent predictor for severe COVID-19 infection. ${ }^{9}$ A study of adults aged 18-34 years identified significantly higher mortality among patients with hypertension. ${ }^{10}$

This study has several limitations. It was limited by the sample size. This study was a single institution study of admitted patients 
which makes generalization difficult. Because of the retrospective design, certain laboratory results were sometimes unavailable on admission, including lactate dehydrogenase, D-dimer, and serum ferritin. Patients with chronic lung disease and conditions associated with immunosuppression were only a small percentage among hospitalized patients. Therefore, the role of some of these variables in predicting mortality from COVID-19 could have been underestimated.

In conclusion, calculation of the qSOFA score bedside at the time of admission can predict mortality among COVID-19 patients aged $\leq 65$ years. These findings can be applied globally, including resource-limited countries. Subsequent research involving multiple study sites and with a larger database can further validate the findings of our study.

\section{Acknowledgments.}

Financial support. This research did not receive any specific grants from funding agencies in the public, commercial, or not-for-profit sectors.

Conflicts of interest. All authors have no association that might pose a conflict of interest.

\section{References}

1. COVID-19 dashboard by the Center for Systems Science and Engineering (CSSE) at Johns Hopkins University (JHU). Johns Hopkins University website. https://coronavirus.jhu.edu/map.html. Published 2020. Accessed October 13, 2020.
2. US Centers for Disease Control and Prevention. Severe outcomes among patients with coronavirus disease 2019 (COVID-19)—United States, February 12-March 16, 2020. Morb Mortal Wkly Rep 2020;69:343-346.

3. Charlson ME, Pompei P, Ales KL, MacKenzie CR. A new method of classifying prognostic comorbidity in longitudinal studies: development and validation. J Chronic Dis 1987;40:373-383.

4. Ioannidis JPA, Axfors C, Contopoulos-Ioannidis DG. Population-Level COVID-19 mortality risk for non-elderly individuals overall and for non-elderly individuals without underlying diseases in pandemic epicenters. Environ Res 2020;188:109890.

5. Freund Y, Lemachatti N, Krastinova E, et al. Prognostic accuracy of Sepsis-3 criteria for in-hospital mortality among patients with suspected infection presenting to the emergency department. JAMA 2017;317:301-308.

6. Jiang SQ, Huang QF, Xie WM, Lv C, Quan XQ. The association between severe COVID-19 and low platelet count: evidence from 31 observational studies involving 7613 participants. Br J Haematol 2020;190(1):e29-e33.

7. Wu Z, McGoogan JM. Characteristics of and important lessons from the coronavirus disease 2019 (COVID-19) outbreak in China: summary of a report of 72,314 cases from the Chinese Center for Disease Control and Prevention. JAMA 2020;323:1239-1242.

8. Kim L, Garg S, O'Halloran A, et al. Risk factors for intensive care unit admission and in-hospital mortality among hospitalized adults identified through the US Coronavirus Disease 2019 (COVID-19)-Associated Hospitalization Surveillance Network (COVID-NET) Clin Infect Dis 2020. doi: 10.1093/cid/ciaa10127.

9. Bhargava A, Fukushima EA, Levine $M$, et al. Predictors for severe COVID19 infection. Clin Infect Dis 2020. doi: 10.1093/cid/ciaa674.

10. Cunningham JW, Vaduganathan M, Claggett BL, et al. Clinical outcomes in young US adults hospitalized with COVID-19. JAMA Intern Med 2020. doi: 10.1001/jamainternmed.2020.5313.

\title{
Coronavirus disease 2019 vaccine hesitancy among children's hospital staff: A single-center survey
}

\author{
Larry K. Kociolek MD, $\mathrm{MSCI}^{1,2}$ (1), Jenny Elhadary PharmD¹, Ravi Jhaveri MD ${ }^{1,2}$, Ami B. Patel MD, MPH ${ }^{1,2}$, \\ Brian Stahulak DNP, MBA ${ }^{1}$ and Jenifer Cartland $\mathrm{PhD}^{1,2}$ \\ ${ }^{1}$ Ann \& Robert H. Lurie Children's Hospital of Chicago, Chicago, Illinois and ${ }^{2}$ Northwestern University Feinberg School of Medicine, Chicago, Illinois
}

The Pfizer-BioNTech COVID-19 (BNT162b2) vaccine was authorized for emergency use on December 11, 2020, ${ }^{1}$ after demonstrating excellent efficacy and safety in a large phase 3 clinical trial in adults and adolescents. ${ }^{2}$ The Advisory Committee on Immunization Practices through the Centers for Disease Control and Prevention then recommended its use, ${ }^{1}$ prompting delivery to US hospitals for healthcare worker vaccination. To help guide our children's hospital workforce vaccine advocacy efforts, we designed a survey assessing frequency of vaccine hesitancy, characteristics of those reporting vaccine hesitancy, specific concerns, and communication preferences.

Author for correspondence: Larry K. Kociolek, E-mail: lkociolek@luriechildrens.org Cite this article: Kociolek LK, et al. (2021). Coronavirus disease 2019 vaccine hesitancy among children's hospital staff: A single-center survey. Infection Control \& Hospital Epidemiology, 42: 775-777, https://doi.org/10.1017/ice.2021.58

\section{Methods}

This survey was performed at the Ann \& Robert H. Lurie Children's Hospital of Chicago, a 360-bed academic free-standing children's hospital with multiple satellite outpatient and surgical centers. On December 21, 2020, the first day of administration of the PfizerBioNTech COVID-19 vaccine to our workforce, a 17-question electronic survey (Supplemental Material online) was sent to all individuals with an active Lurie Children's email address. This survey included all clinical (eg, attending physicians, housekeeping staff, advanced practice staff, and ancillary healthcare workers), and nonclinical (eg, administrative, support, and research) staff. After 3 e-mail reminders were sent, the survey was closed on January 13, 2021. The survey was anonymous, and all questions were optional. During the 2 weeks before the survey, vaccine information was communicated to staff through a virtual town hall, and answers to frequently asked questions were emailed to all staff. Statistical analyses were performed using Stata/IC version 16.0 software (StataCorp, College Station, TX). Descriptive statistics were measured, prevalence ratios were

( ) The Author(s), 2021. Published by Cambridge University Press on behalf of The Society for Healthcare Epidemiology of America. This is an Open Access article, distributed under the terms of the Creative Commons Attribution licence (http://creativecommons.org/licenses/by/4.0/), which permits unrestricted re-use, distribution, and reproduction in any medium, provided the original work is properly cited. 